manner without dogmatism :-change of frequency depends solely on relative motion of source and observer: combined motion of both through a medium does not affect frequency on any theory, so long as the motion is steady. Ordinary aberration is wholly and solely caused by motion of observer relative to path of ray. Is observed velocity of light dependent on motion of observer, too ?. The strength of the relativity position is that no way of performing the experiment is likely to give a positive result, unless truly relative motion is introduced, as by mounting the whole receiver on the end of a revolving arm; and questionably even then. The strength of the ether position is that a relative ether stream past fixed "stations," though undemonstrated, is at least not negatived by this or any other experiment, and may therefore nevertheless be a reality. A philosopher may be able to explain what " reality" means.

\title{
Obituary.
}

Dr. Robert Kidston, F.R.S.

$\mathrm{BY}$ the unexpected death of Robert Kidston on July I3, palæobotany suffers an irreparable loss. Dr. Kidston was still at the height of his activity, and had probably never been busier in his life than when the end came. He was then in South Wales, engaged on his fossil investigations. Equally distinguished in systematic and structural palæobotany, Kidston was the veteran leader in his science, worthy to rank with the great continental masters, such as Zeiller, Grand'Eury, and Nathorst, who had already passed away.

Robert Kidston was born at Bishopston House, Renfrewshire, on June $29, \mathbf{1} 852$. The family removed shortly afterwards to Stirling, where Kidston's life was spent. As a young man Kidston went into business in a bank, but his strong bent for natural history soon turned him towards scientific pursuits. About 1878 he attended botanical classes in the University of Edinburgh. He was then, and remained throughout life, a keen field botanist.

Kidston soon became interested in fossil plants, and his work met with early recognition, for, from I880 onwards, the plant-remains collected by the Geological Survey of Scotland were referred to him. This gave him his first great opportunity.

In Kidston's work as a fossil-botanist two periods may be distinguished. From the beginning up to 1904 he was predominantly a floristic and stratigraphical palæobotanist, and so indeed he continued to be, but from I904 onwards he further took a leading part in morphological and structural investigation, and expressed himself with a wise authority on the great questions of affinity and descent. His work in every field was remarkable for that sound judgment which has so generally characterised the best systematists.

From about 1880 a constant succession of papers on fossil plants was maintained ; only a very few can be mentioned here. In 1886 Kidston was entrusted with the duty of preparing a catalogue of the Palæozoic plants preserved in the British Museum, a valuable work of reference in its time. Thus he was already recognised as our leading systematist in Palæozoic botany.

Kidston always took a special interest in the fructification of ferns and fern-like plants. A paper published in 1887 , "On the Fructification of some Ferns from the Carboniferous Formation," proved to be of exceptional importance, for various reproductive organs described belonged, as Kidston afterwards showed, to the group of the Pteridosperms. Thus, in the case of Neuropteris heterophylla, of which he afterwards discovered the seed, the fructification described in 1887 turned out to be the male form.
The memoir on Lepidophloios (1892) is the leading monograph on that genus of fossil Lycopods. A paper on the various divisions of the Carboniferous rocks as determined by their fossil flora (1893) is a valuable contribution to the geology of that period. Two important memoirs on the fossil flora of the Yorkshire coal-field, on which he had already published a number of reports, appeared in 1896 and 1897 . The second is of remarkable interest, as containing the first complete description of the cones of Sigillaria, and thus finally establishing the true nature of that longdisputed genus.

A general summary of the flora of the Carboniferous Period appeared in $1901-1902$. This was written at a transitional time, when botanists had recognised the Cycadofilices as a class, but were still ignorant of their reproduction. Kidston's remarks do justice to the position at that date.

The second and more brilliant period of Kidston's work opens with his important paper on the fructification of Neuropteris heterophylla (I904). He was the first to demonstrate, by direct proof of continuity, that a fern-like plant of the Coal Age bore seeds. Previous evidence (only slightly antedating Kidston's discovery), however convincing, had been indirect. Kidston, in fact, was a pioneer in this field. A year later $(1905)$ he published a preliminary note on Microsporangia in connexion with the foliage of Lyginodendron and was thus the first to identify the male organs of a "seed-fern." This was followed up in 1905 by his great memoir on the microsporangia of the Pteridospermeæ, a truly admirable work, showing a rare soundness of judgment in discussing the affinities of the newly discovered group.

A purely anatomical memoir on the internal structure of Sigillaria elegans (1908) was the first full and illustrated account of the structure of a ribbed Sigillaria. The work was extended to other species a year later.

Other papers on structural subjects dealt with new species of Dineuron and Botryopteris (early ferns) and with a new Lepidodendron from Pettycur, all of Lower Carboniferous age. Kidston had a special predilection for Lower Carboniferous plants, and was among the first to grasp the full importance of this fine flora.

One of Kidston's later memoirs on the fossil flora of the Staffordshire Coal-Fields (I9I4) includes a number of important discoveries, the most striking being perhaps the pollen-bearing organ of a new Neuropteris, very different from that of $N$. heterophylla.

The mere glance we have taken at a few outstanding papers may serve to show how Kidston's work illuminated every side of Palæozoic botany. His work was fully appreciated on the Continent and was by no 
means confined to his own country. In I9II appeared a fine volume on "Les Végétaux houillers recueillis dans le Hainaut Belge" containing various new genera and species. Another foreign work was his joint book with Dr. Jongmans on the Calamites of Western Europe, published by the Dutch Government. This is a huge monograph; the Atlas published in $\mathrm{r}_{9} \mathbf{5}$ contains $x_{5} 8$ fine plates. So far as the writer is aware, only a portion of the text has appeared.

It remains to notice briefly some of Kidston's work in conjunction with other botanists. One of his most valued colleagues was the late Prof. D. T. GwynneVaughan, whose early death was so severe a loss to botany. Their work on the fossil Osmundaceæ, in five parts, ranging from 1907 to $\mathrm{rgI}_{4}$, is a palæobotanical classic, tracing back the history of the Royal ferns from the Tertiary to the Permian. An admirable photograph is extant, showing the two collaborators at work together on this investigation. Other papers with Gwynne-Vaughan were on a Tempskya from Russia, by far the best account up to that time of this peculiar type of fern-stem, and on a Lower Carboniferous fossil, Stenomyelon tuedianum, discovered by Kidston. This is a model of anatomical work, concise, clear, and exhaustive.

Kidston's work in conjunction with Prof. W. H. Lang, on the Old Red Sandstone plants of the Rhynie Chert-bed (five memoirs, I9I7-I921), was the most important of all, for it demonstrated, in full detail, the structure of the oldest land-plants of which we have any certain knowledge. Never was a great discovery more completely and wisely expounded. The simple plants of Rhynie, thanks to Kidston and Lang's researches, now form the basis of evolutionary work on the plant kingdom.

Other joint memoirs by the same authors were on Hicklingia, a new genus of Early Devonian Plants (1923), and on Palcopitys Milleri (1923), the famous but long neglected "cone-bearing tree" of Hugh Miller. The authors worked out the structure fully, but reserved judgment on the affinities of the plant, which is certainly of astonishingly high organisation for an Early Devonian horizon.

Kidston, at the time of his death, was engaged on what, from a floristic point of view, was to have been the greatest work of his career. This was nothing less than the full description and illustration of all the Carboniferous plants of Great Britain. The series, published by the Geological Survey, was planned to consist of ten memoirs but would, no doubt, have run to more. Four memoirs have been actually published, illustrated by $9 \mathrm{r}$ fine plates. They only embrace a portion of the ferns and fern-like plants. The systematic descriptions are illuminated by admirable observations on broader questions of affinity. It is understood that two more parts are sufficiently advanced for publication, and it is earnestly to be hoped that this magnificent work, a credit alike to the author and to the Department which undertook it, may eventually be brought to completion.

Kidston, among his other accomplishments, was a highly skilled photographer and was thus enabled to illustrate his own works, both systematic and anatomical, in a manner which adds immensely to their value and beauty. In all his writings Kidston showed himself a most fair and generous critic. His splendid collections both of impressions and sections were always available for the use of his scientific colleagues. The present writer, in particular, can testify how much he owes to the constant and generous help of his old friend.

D. H. S.

Prof. Alois Mrazek.

ON November 26, I923, died Dr. Mrázek, professor of zoology in the Charles' (Bohemian) University of Prague. He was born in I868 in Príbram, and originally worked under A. Fric in the patriotic study of the fauna, the aim of which was to increase the knowledge of Bohemian fauna and the extension of the single genera. Later on, under the influence of his second teacher, Prof. Vejdovsky, he devoted his study to typical problems of the period of classical morphology and cytology. He did not limit himself only to the discovery and description of new genera, but he was also interested in the problems, which are typical for the area, of the classical morphology and cytology.

Mrázek directed his study chiefly to the Crustacea and Copepoda, especially to the hermaphroditism of the first and the numerous anatomical details of the antennæ of the second, and the exactness of his work became known in foreign countries, from which valuable material was entrusted to him for research. $\mathrm{He}$ found cystercoids in copepods, and their study brought him to that of the complicated cycles of the evolution of helminthes, and so he became a co-editor of the Journal of Parasitology and a member of the Helminthological Society of Washington. $\mathrm{He}$ investigated also the Sporozoa, Planariæ, Oligochæta, and studied very deeply the life of ants, all work of great exactitude, and discovered fresh-water Nemertines in Bohemia, as well as the only representative of subtropical Temnocephalids in the Lake of Scutari. His beautiful drawings appear frequently in the larger works on cytology. Mrázek was a modern zoologist who was a master of the problems of his time, not a one-sided systematist or a mere morphologist. His work touched also problems of variability, heredity of acquired characters, regeneration, and he devoted a good deal of his time to the study of the relations between the organism and the medium in which it lives, to ecology.

Mrázek was a splendid teacher, full of sacrifice, especially in laboratory work. He published a series of popular lectures on the theory of evolution, and translated Romanes' work, "Darwin and after Darwin." He founded a small but pretty aquarium in his institute, which is visited by thousands of students and other people. While still living, he presented to his institute his rich private library and all his instruments, etc. He was a member of the Bohemian Academy of Science and of the Royal Society of Bohemia. His death is a great loss to our University.

\section{Bohuslav Brauner.}

WE much regret to announce the death of Prof. P. Natorp, emeritus professor of philosophy in the University of Marburg, author of "The Logical Foundations of the Exact Sciences," and leader of the neo-Kantian school, aged seventy. 